\title{
Sports Injuries Patterns In Children And Adolescents According To Their Sports Participation Level, Age And Maturation
}

\section{Lara Costa e Silva ( $\sim$ laras@outlook.pt)}

CIPER, Universidade de Lisboa

Júlia Teles

University of Lisbon

Isabel Fragoso'

University of Lisbon

\section{Research Article}

Keywords: sports injuries, children and adolescents, bone age, peak height velocity, physical activity level

Posted Date: September 13th, 2021

DOI: https://doi.org/10.21203/rs.3.rs-842540/v1

License: (c) (i) This work is licensed under a Creative Commons Attribution 4.0 International License.

Read Full License 


\section{Abstract}

Background: Growth can make young athletes more vulnerable to sports injuries. Increased knowledge about injury profile and its predictors, is an important part of an overall risk management strategy but few studies have produced information.

Methods: Injury profile and physical activity (PA) level information's were obtained by LESADO and RAPIL II questionnaires. They were distributed to 651 participants aged between 10 and 18 years attending four schools. Maturity measures were evaluated through maturity offset (MO) and Tanner-Whitehouse III method. Univariate analysis was used to identify the set of candidate predictors for multinomial logistic regression analysis that was used to determine significant predictors of injury type and body area injury location.

Results: Regarding injury type predictors recreative boys had more chances of having a sprain or a fracture than a strain. Also, recreative and scholar girls had more chances of having a sprain than a strain. As MO decreased, the chances of girls having a strain or a fracture when compared to sprains were higher. For body area location boys with 10-11 years were more likely to have upper limbs injuries than boys of other ages. This was also confirmed by MO. Spine and trunk injuries were more likely to occur in federate and no sports participation girls.

Conclusion: Injury type and body area injury location differed significantly by PA level, age group and MO.

\section{Introduction}

Musculoskeletal injuries are the most common injuries in youth sports ${ }^{1}$. Growth spurt, maturityassociated variation and lack of complex motors skills needed for certain sports are among the risk factors that may play an important role in the growing athlete ${ }^{2,3}$. An epidemic of both acute and overuse injuries, has been considered, as children make the transition for adolescence ${ }^{4}$. Enhanced environment for injury can occur and several authors reported structural and tissue changes that may contribute to this situation ${ }^{1,3-8}$. Asynchronous development of bone and soft tissue take place due to the rapid expansion of bones while growing ${ }^{9}$. The soft tissues do not follow this rapid bone growth and elongate slowly and passively, thus becoming progressively tighter $4,7,8$. Although controversial for some authors, loss of flexibility may occur ${ }^{3,8}$ and tension develops across growth plates, apophyses, muscle-tendon units and joints. This increase in tensile forces can place these structures at risk of injury ${ }^{7,10}$. Also an imbalance between strenght and flexibility can happen. The period in which trunk length and leg length have already increased, but muscles still have not reached their full size, lack of strength can become a potential cause of injury. This may lead to abnormal movement mechanics and to a motor performance decline during peak height velocity (PHV) ${ }^{11}$. Moreover children's bones are weaker ${ }^{7}$, because bone mineralization may lag behind linear growth, thus rendering the bone temporarily more porous ${ }^{8}$. Therefore, there is an increased risk for fractures throughout the bone and growth plate ${ }^{5,7,12}$ confirmed 
through the association between PHV and peak fracture rate $3,12,13$. Likewise, biomechanical and clinical evidence suggests that growth cartilage is less resistant to repetitive microinjury 4,5,8,9,12. During PHV, growth plate is less resilient to traction and compression forces because is predominantly composed by metabolically active chondrocytes, rather than by extracellular matrix ${ }^{10}$. Also, during adolescence, a decrease in coordination and balance may occur, which not only increases the risk of injury, but also influences sports performance ${ }^{7}$.All these events acting singly or together make the immature musculoskeletal system less able to cope with trauma situations and repetitive biomechanical stress ${ }^{4,8}$. Another factor that also has to be issued is maturity-associated variation. Children of the same chronological age may vary considerably in biological maturity status which can make individual differences appear, creating unbalanced competition between early and late maturers contributing to serious injuries ${ }^{3,14}$. Some studies already pointed to the fact that about $1 / 3$ of all players of one age category are not within their normal maturity category 15 .

As children and adolescents participate in sports in record numbers, targeting risk groups is important ${ }^{3}$. Also, increased knowledge about injury profile and its predictors, associated with specific PA exposures is an important part of an overall risk management strategy ${ }^{16}$. So, our aim was to determine injury type and body area injury location predictors in Portuguese youth, engaged in four different levels of sports participation.

\section{Materials And Methods}

Ethics Committee of the Faculty of Human Kinetics approved the research protocol. The recommended principles set by the Helsinki Declaration for scientific research involving human beings were also followed, and before inclusion in the study all subjects' guardians gave their written informed consent. STROBE cross sectional reporting guidelines were followed ${ }^{17}$.

LESADO and Rapil II questionnaires were distributed to 651 participants in four schools, aged between 10 and 17 years involved in different levels of sports participation. LESADO is a self reported questionnaire that gathers information about injury profile. Comes from an extensive literature review on the topic and was adapted and based on epidemiological questionnaires used in Portuguese sports samples ${ }^{18-22}$. As our subjects were children and adolescents, the time to fill out the questionnaires was supervised by the investigator who followed and clarified all doubts, preventing the possibility of bias and interpretation difficulties associated with literacy skills ${ }^{23,24}$. It was also provided a clear definition of injury, based in current epidemiological research ${ }^{25,26}$ and time frame used was six months (September 2011 to March 2012), as recommended in retrospective studies ${ }^{27,28}$. The Biosocial Questionnaire RAPIL II is a parent's self-reported instrument and it was used to measure biosocial variables. It's been used in Portugal in large epidemiological studies ${ }^{29-31}$, and provides information about the daily PA habits of the subject. These data allowed to create four groups of PA levels. The no sports participation group, with no time spent in PA per week (except mandatory physical education classes), the recreative sports group with at least 90 minutes of PA per week being at least $60 \%$ of this volume of recreational activity; the school 
sports group with at least 90 minutes of PA per week being at least $60 \%$ of this volume of school sports activity and the federated sports group with at least 120 minutes of federated activity.

Maturity measures consisted in calculating bone age and maturity offset. Bone age was obtained according to the Tanner-Whitehouse III (TW3) method ${ }^{32}$. Radiographs of left hand and wrist of thirteen bones were taken in a single session, and the maturity ratings were performed by one trained examiner, without knowledge of the chronological age of the subjects.

Maturity offset assessed time before or after PHV according to Mirwald ${ }^{33}$. Maturity offset minus chronological age provides an estimate of the age of PHV. It can be used to group the individuals for years before or after PHV. We used a specific equation for each sex (SEE equation is 0.592 for boys and 0.569 for girls), based on the Canadian and Belgian samples ${ }^{33}$. Applicability of the method appears to be useful during the period of growth acceleration, between $12-15$ years ${ }^{34}$. Chronological age group was defined with the whole year as the midpoint of the range (e.g.,12 years include participants with 11.50 to 12.49 years of decimal age).

The statistical analysis was conducted using SPSS 22.0 software (SPSS Inc., Chicago, IL, USA) and a significance level of $5 \%$ was considered. The dependent variables were injury type $(0=$ strain, $1=$ sprain 2 $=$ fracture $)$ and body area injury location $(0=$ lower limbs, $1=$ upper limbs, $2=$ spine and trunk $)$. Despite some issues that prevent the use of multinomial regression models in case of body area injury location, this technique was initially considered to identify the significant predictors for each sex and for each dependent variable. The evaluated predictors were PA level $(0=$ no sports participation, $1=$ recreative, $2=$ scholar, $3=$ federate), age group $(0=10-11,1=12-13,2=14-15,3=\geq 16$ years $)$, bone age (years) and maturity offset (years). First, univariate analyses of predictors were conducted: Chi-square tests of independence and Kruskal-Wallis tests were used for categorical and quantitative predictors, respectively. The set of candidate predictors for multinomial regression consisted of all the variables that presented $p$ $<.25$ in the univariate analysis ${ }^{35}$, and the backward stepwise method using the likelihood ratio statistic was applied for the model variable selection.

\section{Results}

A total of 651 adolescents participated in this study, aged between 10 and 18 years (Mean $=13.7$; Standard Deviation $=1.8$ years), being 343 boys $(52.7 \%)$ and 308 girls $(47.3 \%)$. Results of the injury profile are presented in Table 1. 
Table 1

Prevalence and injury profile

\begin{tabular}{|c|c|c|}
\hline & Frequency & Percentage \\
\hline Injury Prevalence & 247 & $37,9 \%$ \\
\hline \multicolumn{3}{|l|}{ Body Area Location } \\
\hline Lower Limbs & 107 & $53,8 \%$ \\
\hline Upper Limbs & 58 & $29,0 \%$ \\
\hline Column and Torso & 23 & $11,5 \%$ \\
\hline \multicolumn{3}{|l|}{ Injury Type } \\
\hline Strains & 67 & $33,7 \%$ \\
\hline Sprains & 54 & $27,1 \%$ \\
\hline Fractures & 46 & $23,1 \%$ \\
\hline \multicolumn{3}{|l|}{ Ocurrences } \\
\hline Practice & 174 & $74 \%$ \\
\hline Competition & 61 & $26 \%$ \\
\hline \multicolumn{3}{|l|}{ Causes } \\
\hline Direct Trauma & 123 & $51,9 \%$ \\
\hline Indirect Trauma & 70 & $29,5 \%$ \\
\hline Oversuse & 30 & $12,7 \%$ \\
\hline \multicolumn{3}{|l|}{ Classification } \\
\hline 1st Injury & 123 & $51,9 \%$ \\
\hline Relapse & 59 & $25,0 \%$ \\
\hline Chronic & 38 & $15,9 \%$ \\
\hline \multicolumn{3}{|l|}{ Consequences } \\
\hline Total Recovery & 143 & $60,9 \%$ \\
\hline Conditioned activity, Symptoms or Treatments & 92 & $39,1 \%$ \\
\hline \multicolumn{3}{|l|}{ Severity } \\
\hline$<1$ week & 143 & $54,6 \%$ \\
\hline$\geq 1$ week & 109 & $45,5 \%$ \\
\hline
\end{tabular}




\section{Boys - Predictors of Injury Type}

Significant associations were found only between injury type and PA level $(X 2(4)=12.763, p=.011)$. Backward stepwise methods lead to a multinomial logistic regression model $(X 2(4)=15.165, p=.004)$. The odds of a recreative boy having a sprain rather than strain were 8.84 times more than for a federate boy and the odds of a recreative boy having a fracture rather than a strain were 7.27 times more than for a federate boy. Results can be seen in Table 2 .

\section{Girls - Predictors of Injury Type}

Regarding girls, Kruskal-Wallis tests showed that there were significant differences in bone age $(X 2(2)=$ $9.616, p=.008)$ and maturity offset $(X 2(2)=12.892, p=.002)$ among injury type. Although PA level was not a significant predictor in the univariate analysis, it was considered for the multinomial logistic regression since together with other predictors could be significant. The multinomial logistic regression model achieved two predictors, PA level $(X 2(6)=16.474, p=.011)$ and maturity offset $(X 2(2)=15.115, p$ $=.001)$. The odds of a recreative girl having a sprain rather than a strain were 7.46 times more than a federate girl and the odds of a scholar girl having a sprain rather than a strain were 20.8 times more than a federate girl. Relatively to maturity offset, the odds ratio revealed that as maturity offset decreased by a unit, the change in the odds of having a strain rather than a sprain were 1.71; and of having a fracture rather than a sprain were 2.32. Results are presented in Table 2 and Fig. 1. 
Table 2

Multinomial logistic regression models adjusted for the dependent variable injury type for each sex.

Dependent variable Predictor $\quad B$ (Std Error) $\quad p \quad$ odds ratio $95 \%$ Cl odds ratio

\begin{tabular}{|llllll|}
\hline Type of injury & \multicolumn{5}{c}{ Boys $^{3}$} \\
Sprain & Intercept & $-0.793(0.276)$ & .004 & & \\
\cline { 2 - 6 } & PA level (1) & $0.100(0.672)$ & .882 & 1.105 & $(0.296,4.125)$ \\
\cline { 2 - 6 } & PA level (3) & $2.180(0.838)$ & .009 & 8.842 & $(1.713,45.651)$ \\
\hline Fracture & Intercept & $-0.480(0.250)$ & .055 & & \\
\cline { 2 - 6 } & PA level (1) & $-1.600(1.090)$ & .142 & 0.202 & $(0.024,1.709)$ \\
\cline { 2 - 6 } & PA level (3) & $1.984(0.821)$ & .016 & 7.269 & $(1.455,36.306)$
\end{tabular}

Type of injury ${ }^{2} \quad$ Girls $^{4}$

\begin{tabular}{|llllll|}
\hline Strain & Intercept & $2.272(0.810)$ & .005 & & \\
\cline { 2 - 6 } & Maturity offset & $-0.538(0.224)$ & .016 & 0.584 & $(0.376,0.906)$ \\
\hline PA level(1) & $-1.249(0.756)$ & .098 & 0.287 & $(0.065,1.262)$ \\
\hline PA level(2) & $-2.012(0.824)$ & .015 & 0.134 & $(0.027,0.673)$ \\
\hline Practure & PA level(3) & $-3.029(1.239)$ & .015 & 0.048 & $(0.004,0.549)$ \\
\hline Intercept & $2.050(0.895)$ & .022 & & \\
\hline Maturity offset & $-0.842(0.253)$ & .001 & 0.431 & $(0.262,0.707)$ \\
\hline PA level(1) & $-1.869(0.974)$ & .055 & 0.154 & $(0.023,1.041)$ \\
\hline PA level(2) & $-1.541(0.932)$ & .098 & 0.214 & $(0.034,1.330)$ \\
\hline PA level(3) & $-0.572(0.945)$ & .545 & 0.564 & $(0.089,3.596)$ \\
\hline
\end{tabular}

${ }^{1}$ The reference category is strain.

2 The reference category is sprain.

${ }^{3}$ Model $X^{2}(4)=15.165, p=.004 ;$ Cox \& Snell $R^{2}=.120 ;$ Nagelkerke $R^{2}=.135 ;$ McFadden $R^{2}=.059$.

${ }^{4}$ Model $X^{2}(8)=28.770, p<.001 ;$ Cox \& Snell $R^{2}=.290 ;$ Nagelkerke $R^{2}=.328 ;$ McFadden $R^{2}=.158$.

\section{Boys - Predictors of Body Area Injury Location}

A significant association was found between body area injury location and age group $(X 2(6)=13.587, p$ $=.033$ ). Boys with 10-11 years were more likely to have upper limbs injuries than boys of the other age groups and less likely to have lower limbs injuries than boys of age groups 14-15 and $\geq 16$. 
KruskalWallis tests also revealed that significant differences emerged in maturity offset $(X 2(2)=6.014, p$ $=.049$ ). Post hoc tests showed that the differences in maturity offset were between upper limbs and lower limbs $(p=.045)$. See Fig. 2 .

\section{Girls - Predictors of Body Area Injury Location}

A significant association was detected between body area injury location and PA level $(X 2(6)=14.587, p$ $=.022$ ). Federate girls were more likely to have spine and trunk injuries than scholar and recreative girls, and girls with no sport participation were more likely to have spine and trunk injuries than recreative girls. See Fig. 3.

The reduced number of spine and trunk injuries for both boys and girls prevented the use of multinomial logistic regression in case of body area injury location.

\section{Discussion}

Injuries in school age children from different PA backgrounds have a specific identity, being age, PA level and maturation important predictors of body area injury location and injury types. With respect to PA level we have found different results for each sports group. Girls in the no sports participation group presented more chances of having a spine or trunk injury. Scholar girls were more likely to have sprains than strains. Boys and girls of the recreative group were more likely to have sprains, and boys also fractures, than strains. Federated girls and boys reported more strains, rather than sprains or fractures. These federated girls were also more likely to have spine and trunk injuries. As maturity offset is concern, strains and fractures were more likely to occur in girls near the PHV. In boys upper limbs injuries were more likely to occur before PHV, and lower limbs injuries after PHV. Group age results were very similar to maturation results. Boys with 10-11 years were more likely to have upper limbs injuries than boys of the other age groups and less likely to have lower limbs injuries than boys of age groups $14-15$ and $\geq 16$.

Few studies have produced solid information about sports injuries in children and adolescents. Identifying associations between maturation, PA level and age and injury type and body area location, allows health professionals to detect individuals who may be at risk. Each sport group presented a specific injury profile and PHV proved to be an important milestone for the evaluation of the injury pattern in adolescents of both sexes. Due to the variation observed in growth and maturation between adolescents, chronological age is an incomplete indicator for injury risk. Inter-individual variability in biological maturation corresponds to variation in readiness for sport and by inference in vulnerability to specific injuries. Although all preventive measures to prevent recall bias have been taken, the study methodology is still retrospective and based on memories associated with the injury. Also, difficulties can be encountered when using survey measures with children associated with their low literacy skills.

\section{PA level}


Injuries are normally related with the specificities of the practiced activity $18,19,36$. The distribution through the different levels of sports participation seems to be one of the key variables in regard to injury type. Scholar girls were more likely to have sprains rather than strains 20.8 times. Like it was proven by several studies, sprains are one of the most common injuries sustained by young athletes ${ }^{2,36}$ and highly related with traumatic mechanisms ${ }^{37}$, due to joint stiffness and abnormal movement mechanics during growth ${ }^{11}$. The traumatic nature of injuries found in our data can be a factor that contributes to this pattern, and sex difference can be explained by the higher involvement of girls in scholar sports ${ }^{19}$. In addition, concerns about school sports have been raised due to the poor quality of the playing fields, inappropriate protective equipment and inefficient supervision ${ }^{6}$. Boys and girls of the recreative group were 8.84 and 7.46 times respectively more likely to have sprains than strains, and boys had 7.27 times more chances of having a fracture rather than strains. The concerns raised in regard to scholar sports about environmental, equipment and supervision issues are also present in recreative sports. Also, recreative sports can be practiced in a variety of settings, which can add complexity to injury patterns. As fractures in boys are concerned, younger males tend to sustain during sports practice, more accidental injuries, especially fractures, than girls, older children and adults ${ }^{38}$. Recent studies reported that fractures represented $10 \%$ to $25 \%$ of all injuries sustained by high school athletes and were more common among males ${ }^{13,26}$. The high incidence of fractures in childhood result from a transient deficit in bone mass related to longitudinal growth. The pubertal period of transient fragility has also been suggested to be due to an increased bone porosity ${ }^{13}$. Federated girls and boys reported more strains, rather than sprains or fractures. Federated athletes sustain a greater proportion of soft tissue injuries and a large percentage can be classified as overuse. Recent studies are beginning to emphasize and describe overuse injuries as the most significant mechanism of injury in organized sports. The increasingly highly competitive nature of youth sports, increased periods of extensive training, repetitive movements, sport specialization and participation in large numbers of competitive events ${ }^{19,39,40}$ have made overuse injuries a growing reality. Subjects who have not developed some skills like strength, endurance, and motor control may be at increased injury risk as they begin or get more involved in a specific sport ${ }^{12}$. Also in organized competition, the child may feel an expectation to continue and therefore be more likely to push through pain or soreness. Structured sports training and competition do not always allow adequate rest periods for a developing child ${ }^{10}$.

Girls in the no sports participation and federated groups presented more chances of having a spine or trunk injury $(X 2(6)=14.587, p=.022)$. It has already been found associations between low back pain (the most prevalent spine and trunk injury) and the number of hours spent watching television and the number of hours spent practicing competitive sports ${ }^{41}$. Low levels of PA and sedentary lifestyle can be considered a risk factor. Physical inactivity can result in decreased strength, bone mineral content, flexibility and coordination, and these factors can contribute to the appearance of symptoms, especially in girls ${ }^{42,43}$. Sedentary lifestyle is also related to increased body fat mass. Several researchers have claimed that female samples with higher levels of localized abdominal fat are more prone to suffer from spine disorders ${ }^{44,45}$. On the other hand, as already addressed, it is also common scientific studies to 
report young athletes as a risk group for spine dysfunction 46,47 . Low back pain in athletes is usually directly related to sports practice. Symptoms or degenerative changes in the spine can occur. The protective effect of sports participation disappears, manifesting a harmful effect with high training volumes and intensities. Functional or repetitive overload and/or charges introduced early, not adapted to the growth and physiological characteristics of the athlete are usually the main causes ${ }^{48,49}$.

\section{Maturity Offset}

As $\mathrm{MO}$ is concern, strains and fractures were more likely to occur in girls near the PHV. It's consensual that around the PHV period, adolescents are vulnerable to injuries ${ }^{14,18,50}$. Physiological loading is beneficial for the bones, but excessive load may produce serious injuries, like strains ${ }^{50}$.

An increase in traumatic injuries takes place mainly during the year of PHV, while the increase in overuse injuries persists in the year after PHV. A period in which trunk length and leg length have already increased, but muscles still have to reach their full size and strength creates an imbalance between strength and flexibility. This may lead to abnormal movement mechanics and a decline in performance on motor tasks during the interval of PHV. Possibly, this temporarily decline in essential motor performance during years of maximal growth contributes to an increase in traumatic injuries ${ }^{11}$. Additionally a decrease in bone mineral density occurs before the attainment of PHV and correlates with acute fracture episodes ${ }^{10-13}$. In healthy girls, fractures during childhood and adolescence are more frequent with later than earlier menarche. This higher fracture incidence in late maturers is associated with significant deficits in bone mass, microstructure and strength estimates ${ }^{13}$. These factors that are reported as responsible for an increase in traumatic injuries (joint stiffness, decreased bone density, abnormal movement mechanics) disappear in the year after PHV, in contrast to factors contributing to overuse injuries. As overuse injuries are concerned, authors have explained its causes from a biomechanical perspective. First, changes in bones limb mass typically occur before changes in muscle tissue. If muscles, tendons and apophyses adapt slowly, and activities are performed repetitively, those tissues are not immediately able to deal with the increased stress and overuse injuries may occur, leaving a period of increased susceptibility after PHV ${ }^{11}$. Moreover, it should be noted that girls present higher overuse injury rates than boys [32]. Relatively to body area injury location, only boys presented significant results. Boys' upper limbs injuries were more likely to occur before PHV, and lower limbs injuries after PHV $(p=.045)$. These results reflect the type of injury associated to growth velocity during adolescence, and its relation to body area injury location, where traumatic upper limb bony injuries can occur more often in children/adolescents before PHV, and soft tissue lower limb injuries in adolescents after PHV. It is known that significantly larger proportion of injuries sustained by older children are to soft tissues when compared with younger athletes. Younger athletes are more likely to have bone fractures and are treated for a greater proportion of traumatic injuries ${ }^{5}$. These fractures are normally located in the upper limbs ${ }^{26}$.During puberty, the asynchrony between the acceleration of standing height and bone mineral content gain is also associated in the distal radius with a transient cortical deficit with an increased porosity that may well contribute to the adolescent increased incidence in forearm fractures ${ }^{13}$. Also, 
during growth, some subjects experience a decrease in coordination and balance and lack complex motor skills, what may predispose them to falls, contact injuries and possible traumatic upper limb injuries. On the other hand, increased stress on the muscle-tendon-bone junctions, ligaments, and growth cartilage occurs as the changes in the length, mass, and moment of inertia of the extremities take place with growth. Although tissue and structural dynamic equilibrium begins to be reached after PHV some degree of fragility still persists. The increase in strength needed to accommodate these changes may not occur in a uniform pattern and may enable the child or teenager to continue to generate the same limb speed as before the growth spurt. These complex factors and combinations of growth, strength, load, sport training and competition create situations conducive to the development of overuse injuries, especially in lower limbs ${ }^{12}$.

\section{Age Group}

Group age results reflect the maturation results. Boys with 10-11 years were more likely to have upper limbs injuries than boys of the other age groups and less likely to have lower limbs injuries than boys of age groups $14-15$ and $\geq 16(X 2(6)=13.587, p=.033)$. This pattern is highly related to the PHV process, with all the structural and tissue changes already explained. Some authors are starting to recognize that the effect of age on injury risk may be trivial at these ages ${ }^{14,18}$.

\section{Conclusion}

Some injury risk factors are unique to the growing athlete. Increased knowledge about injury characteristics associated with specific PA exposures and maturation variables are an important part of an overall risk management strategy. A specific injury profile was present at all levels of PA participation. PHV was a significant predictor of injury patterns in adolescents of both sexes. Chronological age may not be an absolute indicator for injury risk and the assessment of maturation is a more complete measure. Evaluation of biological maturation should be strongly encouraged.

\section{Abbreviations}

PA - physical activity

MO - maturity offset

PHV - peak height velocity

SEE - standard error of estimate

\section{Declarations}

Ethics approval and consent to participate: Ethics Committee of the Faculty of Human Kinetics approved the research protocol. The recommended principles set by the Helsinki Declaration for scientific research 
involving human beings were also followed, and before inclusion in the study all subjects' guardians gave their written informed consent. The study is according to STROBE guidelines.

Consent for publication: Not applicable.

Availability of data and material: The datasets used and/or analysed during the current study are available from the corresponding author on reasonable request. They can be presented as supplementary information files.

Competing interests and authors' contributions: This work has received founding from the Portuguese foundation of science and technology, which had no involvement in the study design, collection, analysis and interpretation of data, writing of the report, and decision to submit the paper for publication. Each author listed on the manuscript, Lara Costa e Silva, Isabel Fragoso and Júlia Teles had read and approved the final version of the manuscript and take full responsibility for the manuscript. All authors contributed in an active way for the elaboration of the study fulfilling the four criteria recommended by the ICMJE. The authors have no conflicts of interest to declare.

\section{Acknowledgements:}

We would like to express our immeasurable gratitude to Ana Lúcia Silva and João Albuquerque for helping in data collection, and Carlos Barrigas for evaluating all x rays. We also thank to Escola Básica 2,3 Professor Delfim Santos, Agrupamento de escolas de Portela e Moscavide and Escola Secundária Quinta do Marquês, for making both their infrastructures and students available for the study and to all participants for their time and effort. Lara Costa e Silva, Ana Lúcia Silva e João Albuquerque were supported by a scholarship from the Portuguese Foundation for Science and Technology (SFRH/BD/77408/2011), (SFRH/BD/91029/2012), and PTDC/DES/113156/2009, respectively) and by the Interdisciplinary Center for the Study of Human Performance (CIPER).

\section{References}

1. Patel D, Nelson T. Sports injuries in adolescents. Med Clin North Am. 2000;84(4):983-1007.

2. Adirim T, Cheng T. Overview of injuries in the young athlete. Sport Med. 2003;33(1):75-81.

3. Maffulli N, Caine D. The Epidemiology of Children's Team Sports Injuries. Med Sport Sci. 2005;49:1-8. doi:10.1159/000085330

4. Gerrard D. Overuse injury and growing bones: the young athlete at risk. Br J Sports Med. 1993;27(1):1418. doi:10.1136/bjsm.27.1.14

5. Best T. Muscle-tendon injuries in young athlete. Clin Sport Med. 1995;14(3):669-686.

6. Baxter-Jones A, Maffulli N, Helms P. Low injury rates in elite athletes. Arch Dis Child. 1993;68(1):130132. 
7. Merkel D. Youth sport: positive and negative impact on young athletes. Open access J Sport Med. 2013:151-160. http://www.ncbi.nlm.nih.gov/pmc/articles/PMC3871410/.

8. Micheli LJ, Klein JD. Sports injuries in children and adolescents. Br J Sports Med. 1991;25(1):6-9. doi:10.1136/bjsm.25.1.6

9. Cohen E, Sala D. Rehabilitation of pediatric musculoskeletal sport-related injuries: a review of the literature. Eur J Rehabil Med. 2010;46:133-146.

10. Jayanthi NA, LaBella CR, Fischer D, Pasulka J, Dugas LR. Sports-Specialized Intensive Training and the Risk of Injury in Young Athletes: A Clinical Case-Control Study. Am J Sports Med. 2015;43(4):794-801. doi:10.1177/0363546514567298

11. Sluis A van der, Elferink-Gemser MT, Coelho-e-Silva MJM, et al. Sport Injuries Aligned to Peak Height Velocity in Talented Pubertal Soccer Players. Int J Sports Med. 2014;35(4):351-355. doi:10.1055/s-00331349874

12. DiFiori J. Overuse injuries in children and adolescents. Curr Sport Med Rep. 2010;9(6):372-378.

13. Bonjour JP, Chevalley T. Pubertal timing, bone acquisition, and risk of fracture throughout life. Endocr Rev. 2014;35(5):820-847. doi:10.1210/er.2014-1007

14. Bowerman E, Whatman C, Harris N, Bradshaw E, Karin J. Are maturation, growth and lower extremity alignment associated with overuse injury in elite adolescent ballet dancers? Phys Ther Sport. 2014;15(4):234-241. doi:10.1016/j.ptsp.2013.12.014

15. Faude $O$, Robler R, Junge A. Football injuries in children and adolescent players: Are there clues for prevention? Sport Med. 2013;43(9):819-837. doi:10.1007/s40279-013-0061-x

16. Abernethy L, MacAuley D. Impact of school sports injury. Br J Sport Med. 2003;37(4):354-355. doi:10.1136/bjsm.37.4.354

17. von Elm E, Altman DG, Egger M, Pocock SJ, Gøtzsche PC, Vandenbroucke JP. The Strengthening the Reporting of Observational Studies in Epidemiology (STROBE) statement: guidelines for reporting observational studies. J Clin Epidemiol. 2008;61(4):344-349. doi:10.1016/j.jclinepi.2007.11.008

18. Costa e Silva L, Fragoso MI, Teles J. Physical Activity-Related Injury Profile in Children and Adolescents According to Their Age, Maturation, and Level of Sports Participation. Sports Health. 2017;9(2):118-125. doi:10.1177/1941738116686964

19. Costa e Silva L, Fragoso I, Teles J. Prevalence and injury profile in Portuguese children and adolescents according to their level of sports participation. J Sports Med Phys Fitness. 2018;58(3):271279. 
20. Azevedo A, Oliveira R, Fonseca J. Lesões no sistema musculo-esquelético em bailarinas profissionais, em Portugal, na temporada 2004/2005. Rev Port Fisioter no Desporto. 2007;1(1):32-37.

21. Goldberg A, Loroz M, Smith A, Ganley T. Injury surveillance in young athletes: a clinician's guide to sports injury literature. Sport Med. 2007;37(3):265-278.

22. Pires D, Oliveira R. Lesões no sistema musculo-esquelético em tenistas portugueses. Rev Port Fisioter no Desporto. 2010;4(2):15-22.

23. Nicholl JP, Coleman P, Williamst BT. The epidemiology of sports and exercise related injury in the United Kingdom. Br J Sports Med. 1995;29(4):232-238. doi:10.1136/bjsm.29.4.232

24. Siesmaa EJ, Blitvich JD, White PE, Finch CF. Measuring children's self-reported sport participation, risk perception and injury history: Development and validation of a survey instrument. J Sci Med Sport. 2011;14(1):22-26. doi:10.1016/j.jsams.2010.04.006

25. Changstrom BG, Brou L, Khodaee M, Braund C, Comstock RD. Epidemiology of Stress Fracture Injuries Among US High School Athletes, 2005-2006 Through 2012-2013. Am J Sports Med. 2015;43(1):26-33. doi:10.1177/0363546514562739

26. Swenson DM, Henke NM, Collins CL, Fields SK, Comstock RD. Epidemiology of United States High School Sports-Related Fractures, 2008-09 to 2010-11. Am J Sports Med. 2012;40:2078-2084. doi:10.1177/0363546512453304

27. Schneider S, Yamamoto S, Weidmann C, Brühmann B. Sports injuries among adolescents: Incidence, causes and consequences. J Paediatr Child Health. 2012;48(10):183-189. doi:10.1111/j.14401754.2012.02578.x

28. Gabbe BJ, Finch CF, Bennell KL, Wajswelner $\mathrm{H}$. How valid is a self reported 12 month sports injury history? Br J Sports Med. 2003;37(6):545-547. doi:10.1136/bjsm.37.6.545

29. Varela-Silva M, Fragoso I, Vieira F. Growth and nutritional status of Portuguese children from Lisbon, and their parents. Notes on time trends between 1971 and 2001. Ann Hum Biol. 2010;37:702-716.

30. Massuça L, Fragoso I. Study of Portuguese Handball Players of different Playing Status. A Morphological and Biosocial Perspective. Biol Sport. 2011;28:37-44.

31. Fragoso I, Vieira F, Barrigas C, et al. Influence of Maturation on Morphology, Food Ingestion and Motor Performance Variability of Lisbon Children Aged Between 7 to 8 Years. In: Olds T, Marfell- Jones M, eds. Kinanthropometry X. Proceedings of the 10th Conference of the International Society for the Advancement of Kinanthropometry (ISAK). London: Routledge; 2007:9-24.

32. Tanner J, Goldstein H, Cameron N. Assessment of Skeletal Maturity. London: Saunders; 2001. 
33. Mirwald RL, Baxter-jones ADG, Bailey DA, Beunen GP. An assessment of maturity from anthropometric measurements. Med Sci Sport Exerc. 2002;34(4):689-694.

34. Malina R, Koziel S. Validation of maturity offset in a longitudinal sample of Polish boys. J Sport Sci. 2014;32(5):424-437. doi:10.1080/02640414.2013.828850.

35. Hosmer D, Lemeshow S, Sturdivant R. Applied Logistic Regression. 3rd Editio. Hoboken: Wiley.; 2013.

36. Rosa B, Asperti A, Helito C, Demange M, Fernandes T, Hernandez A. Epidemiology of Sports injuries on a Collegiate Athletes At A Single Center. Acta Ortop Bras. 2014;22(6):321-324.

37. Schneider S, Seither B, Tönges S, Schmitt H. Sports injuries: population based representative data on incidence, diagnosis, sequelae, and high risk groups. Br J Sports Med. 2006;40(4):334-339; discussion 339. doi:10.1136/bjsm.2005.022889

38. Myer G, Quatman C, Khoury J, Wall E, Hewett T. Youth Versus Adult "Weightlifting" Injuries Presenting to United States Emergency Rooms: Accidental Versus Nonaccidental Injury Mechanisms. J Strength Cond Res. 2009;23(7):2054-2060. doi:10.1519/JSC.0b013e3181b86712.Youth

39. Difiori JP, Benjamin HJ, Brenner J, et al. Overuse Injuries and Burnout in Youth Sports: A Position Statement from the American Medical Society for Sports Medicine. Clin J Sport Med. 2014;24(1):3-20.

40. Schroeder AN, Comstock RD, Collins CL, Everhart J, Flanigan D, Best TM. Epidemiology of Overuse Injuries among High-School Athletes in the United States. J Pediatr. 2015;166(3):600-606. doi:10.1016/j.jpeds.2014.09.037

41. Kujala U, Salminen J, Taimela S, Oksanen A, Jaakkola L. Subject characteristics and low back pain in young athletes and nonathletes. Med Sci Sports Exerc. 1992;24(6):627-632.

42. Sjolie J, Ljunggren A. The significance of high lumbar mobility and low lumbar strength for current and future low back pain in adolescents. Spine (Phila Pa 1976). 2001;26(23):2629-36.

43. Adams A, Mannion A, Dolan P. Personal Risk Factors for First Time Low Back Pain. Spine (Phila Pa 1976). 1999;24(23):2497-2505.

44. Lean M, Han T, Seidell J. Impairment of health and quality of life in people with large waist circumference. Lancet [Internet]. 1998;351(9106):853-856.

45. Hicks G. Trunk Muscle Composition as a Predictor of Reduced Functional Capacity in the Health, Aging and Body Composition Study: The Moderating Role of Back Pain. Journals Gerontol Ser A Biol Sci Med Sci. 2005;60(7):882-887.

46. Duggleby T, Kumar S. Epidemiology of juvenile low back pain: a review. Disabil Rehabil. 1997;19(12):505-512. 
47. Cakmak A, Yucel B, Ozyalçn S, et al. The Frequency and Associated Factors of Low Back Pain Among a Younger Population in Turkey. Spine (Phila Pa 1976). 2004;29(14):1567-1572.

48. Mortimer M, Wiktorin C, Pernol G, Svensson H, Vingard E, MI. CM-N study group. Sports activities, body weight and smoking in relation to low-back pain: a population-based case-referent study. Scand $J$ Med Sci Sport. 2001;11(3):178-84.

49. Limon S, Valinsky L, Ben-Shalom Y. Children at Risk. Risk Factors for Low Back Pain in the Elementary School Environment. Spine (Phila Pa 1976). 2004;29(6):697-702.

50. Shanmugam C, Maffulli N. Sports injuries in children. Br Med Bull. 2008;86:33-57. doi:10.1093/bmb/ldn001

\section{Figures}

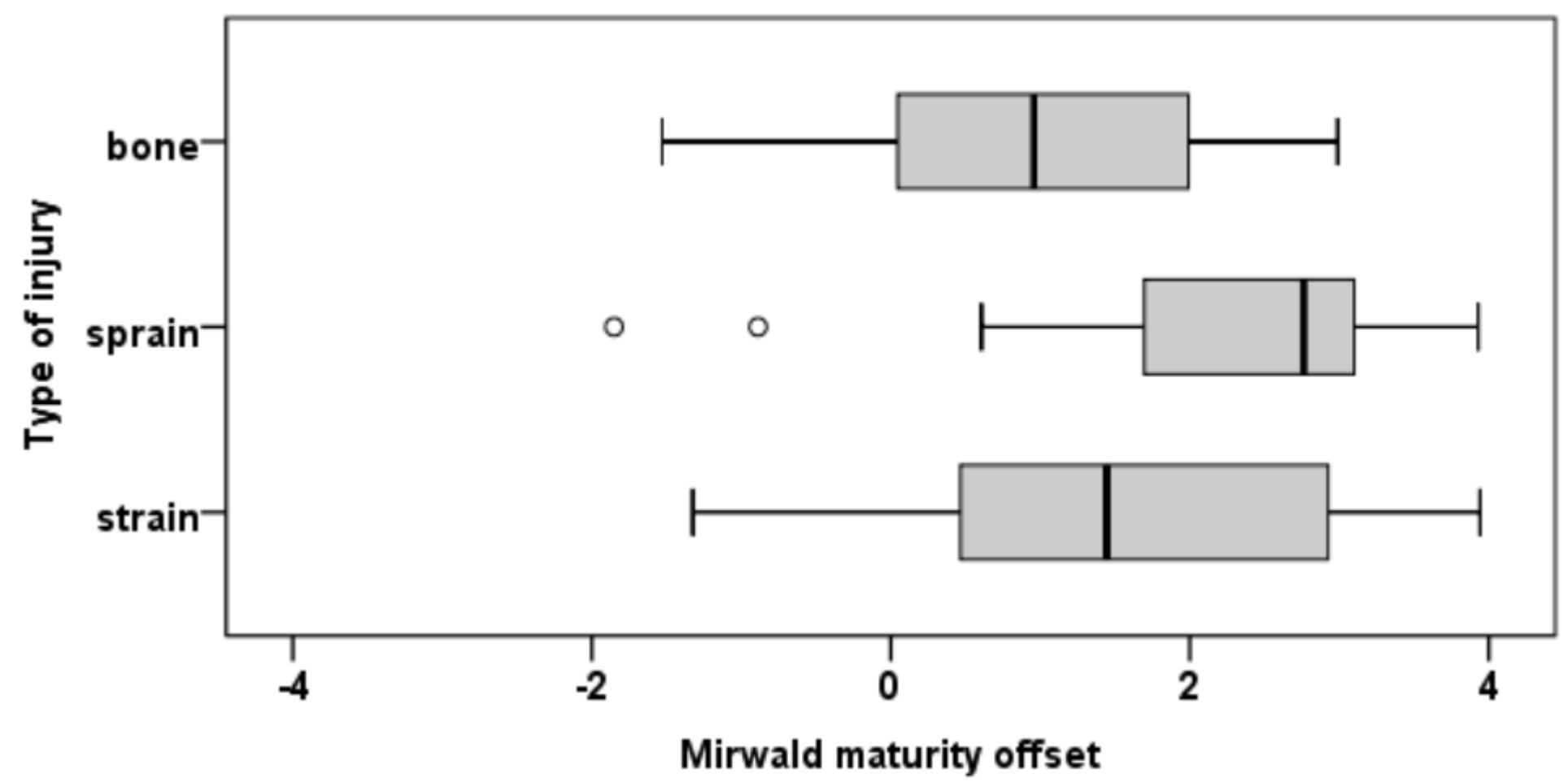

Figure 1

Boxplots of maturity offset for girls by type of injury. 


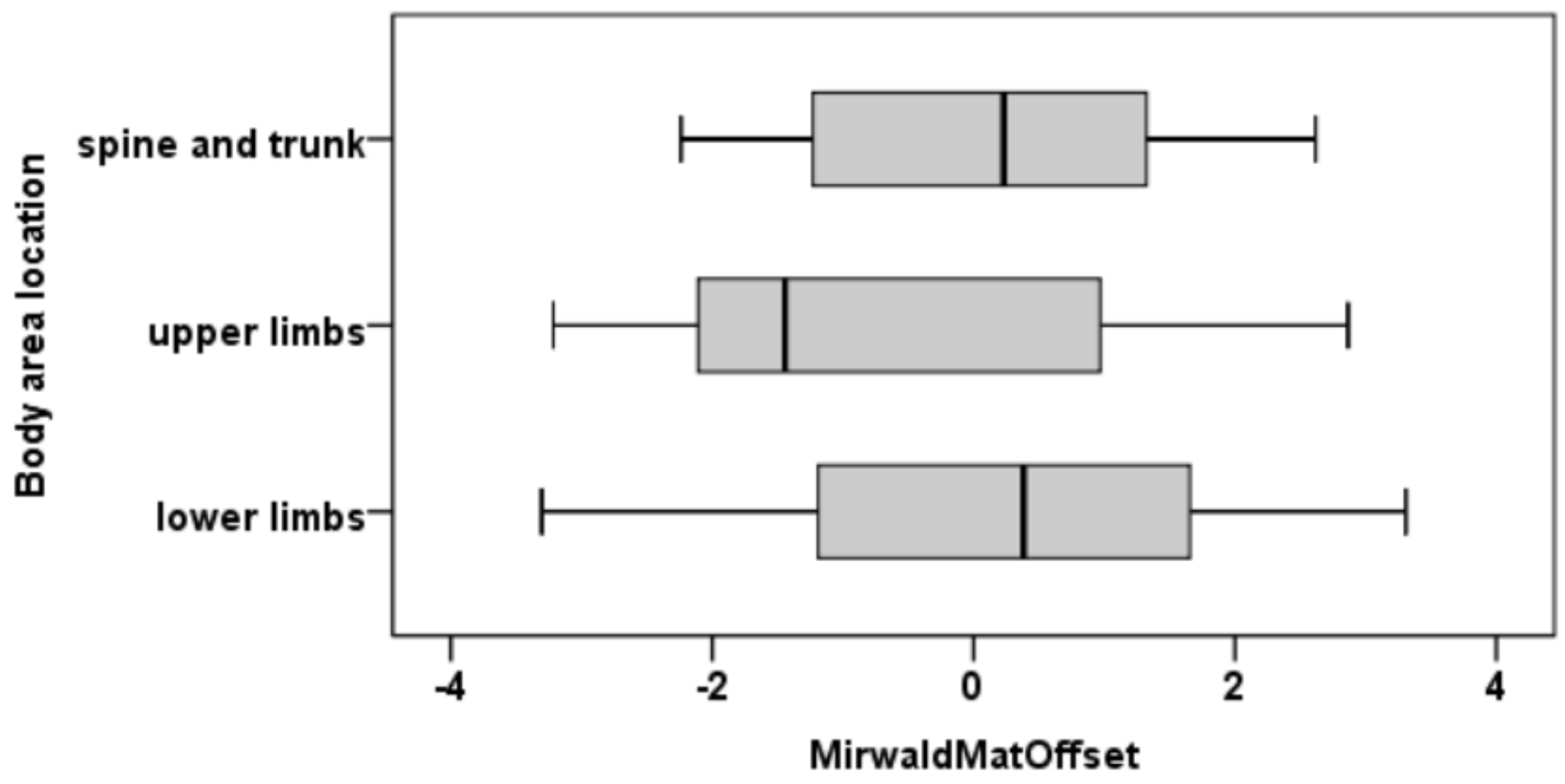

Figure 2

Boxplots of maturity offset for boys by body area location. 


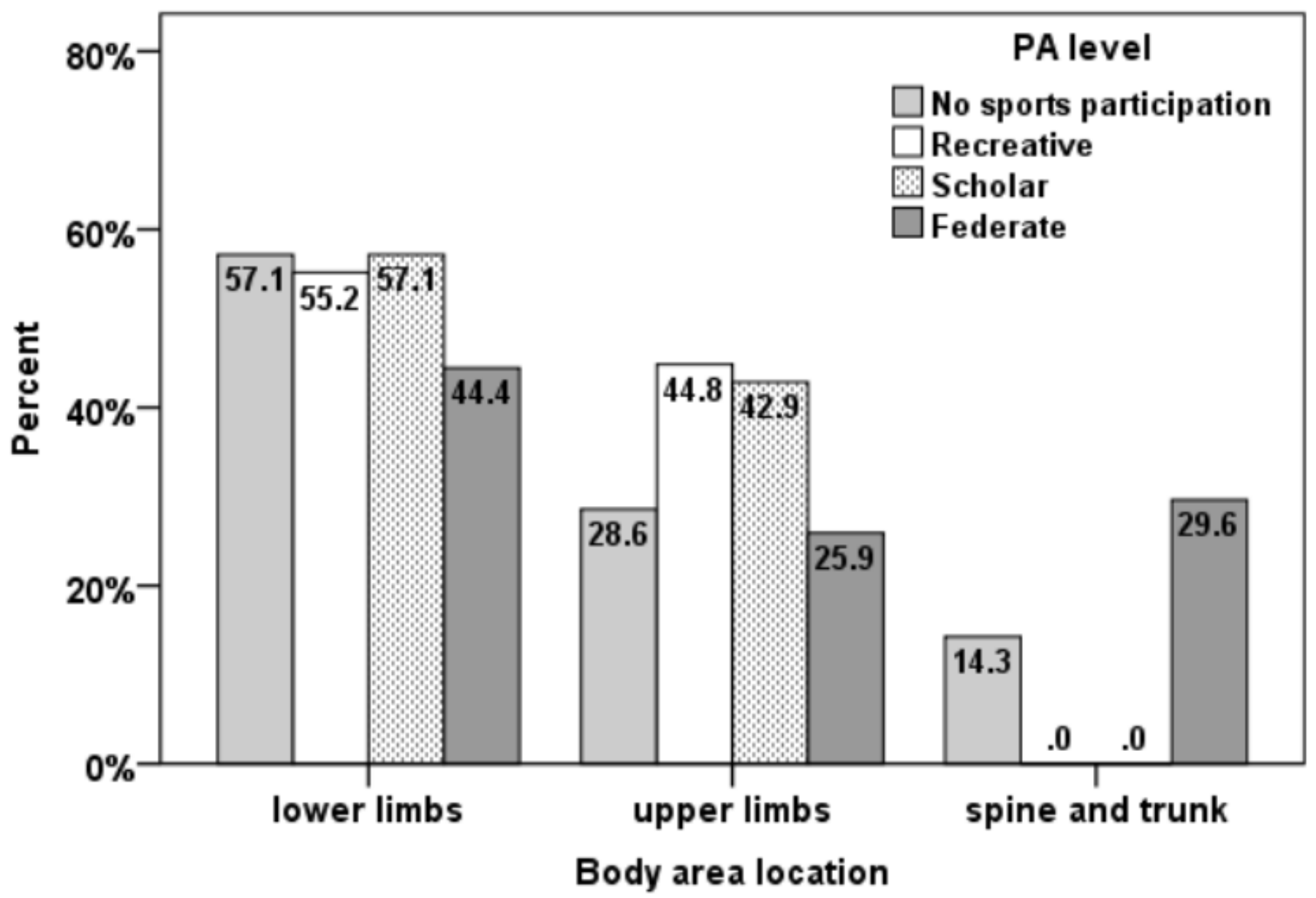

Figure 3

Girls percentage of injuries by body area location for each PA level. 